Revista de Derecho Público: Teoría y Método

\title{
EL DERECHO ADMINISTRATIVO EUROPEO COMO SISTEMA*
}

\section{THE SYSTEM OF EUROPEAN ADMINISTRATIVE LAW}

\author{
Luis Arroyo Jiménez \\ Profesor Titular de Derecho Administrativo \\ Cátedra Jean Monnet de Derecho Administrativo Europeo y Global \\ Universidad de Castilla-La Mancha \\ luis.arroyo@uclm.es
}

RESUMEN: El Derecho administrativo europeo es un instrumento de dirección de procesos sociales que, en su estado actual, presenta algunas debilidades importantes. En este artículo se sugiere que una vía para perfeccionarlo es desarrollar su teoría general a partir de un pensamiento orientado al sistema. En particular, la finalidad del trabajo es analizar cómo debe acometerse esa tarea. Después de presentar sus fundamentos teóricos y metodológicos, se pasa a continuación a identificar alguno de los elementos más relevantes sobre los que tiene que desarrollarse la sistematización del Derecho administrativo europeo. A tal efecto se distingue entre los de carácter sustantivo -principios constitucionales, fines legislativos y criterios discrecionales-y los de carácter estructural-organización, procedimiento y formas jurídicas de actuación-. El artículo concluye con una recapitulación de las conclusiones obtenidas y una reflexión final acerca del alcance y los límites de la sistematización del Derecho administrativo europeo.

PALABRAS CLAVE: Derecho administrativo; Unión Europea, Sistematización; Metodología; Principios; Estructuras administrativas.

ABSTRACT: European administrative law is an instrument aimed at steering social processes that, in its current state, presents some important flaws. This article suggests a way to improve it, by develo-

* Este artículo se ha elaborado en el marco del proyecto del Plan Nacional de I+D Administrative Law Beyond the State (PGC2018-101476-B-I00), así como de la Cátedra Jean Monnet European Administrative Law in Global Perspective (611124-EPP-1-2019-1-ES-EPPIMO-CHAIR), de los que el autor es investigador principal. 
ping a general theory of European administrative law in a system-oriented approach. In particular, the purpose of this paper is to explore how this task should be undertaken. After describing its theoretical and methodological foundations, the article identifies next some of the most relevant building blocks on which systematization of European administrative law has to unfold. In this respect, a distinction is made between elements of a substantive nature -constitutional principles, legislative goals, and discretional criteria- and elements of a structural nature -forms of organization, types of procedure, and legal forms of action. The article ends with a summary of some conclusions, and with a final consideration on the scope and limits of European administrative law's systematization.

KEYWORDS: Administrative law; European Union; Systematisation; Methodology; Principles; Administrative structures.

SUMARIO: 1. INTRODUCCIÓN.-2. EL SISTEMA DEL DERECHO ADMINISTRATIVO EUROPEO: 2.1. Concepto. 2.2. Funciones. 2.3. Características.-3. LA SISTEMATIZACIÓN DEL DERECHO ADMINISTRATIVO EUROPEO: 3.1. Alcance y límites. 3.2. Justificación. 3.3. Elementos.-4. LA METODOLOGÍA DE LA SISTEMATIZACIÓN: 4.1. Deducción. 4.2. Inducción. 4.3. Apertura.-5. LA FUNCIÓN EN EL SISTEMA DEL DERECHO ADMINISTRATIVO EUROPEO: 5.1. Principios constitucionales. 5.2. Dirección legislativa. 5.3. Discrecionalidad administrativa.-6. LA FORMA EN EL SISTEMA DEL DERECHO ADMINISTRATIVO EUROPEO: 6.1. Organización. 6.2. Procedimientos. 6.3. Formas jurídicas.-7. CONCLUSIONES.

\section{INTRODUCCIÓN}

En un trabajo reciente, E. Chiti ha defendido que el Derecho administrativo europeo está fracasando en tres de sus tareas más importantes: alcanzar un equilibrio adecuado entre la promoción de la convergencia y la protección de la diversidad; racionalizar jurídicamente la atribución y el ejercicio del poder administrativo; y lograr una cierta estabilidad de las pautas de actuación de la administración europea ${ }^{1}$. La tesis que aquí se mantiene es que, en gran medida, estos y otros problemas del Derecho administrativo europeo tienen su origen en un déficit de sistematización. La reflexión académica acerca del Derecho administrativo europeo se ha centrado fundamentalmente en el análisis de los diferentes regímenes sectoriales de la administración europea. Cuando ha ido más allá de esto, su labor suele agotarse en la interpretación de las puntuales resoluciones del Tribunal de Justicia de la Unión Europea y de las escasas normas de Derecho secundario que tienen carácter transversal.

Esta labor es necesaria, pero no suficiente. Solo podremos lograr avances significativos en la tarea de comprender y mejorar el Derecho administrativo europeo si esos esfuerzos se realizan en el marco de una teoría general del Derecho administrativo que les dote de estructura y orientación. Y ello pasa por incrementar la relevancia

1 Eduardo CHITI, "Is EU Administrative Law Failing in some of Its Crucial Tasks?", European Law Journal, vol. 22, núm. 5, 2016, pp. 576-596. 
del pensamiento sistemático en el desarrollo teórico del Derecho administrativo europeo. En particular, la finalidad de este artículo es analizar cómo debe acometerse esta tarea. En las secciones que siguen a continuación se plantean sus fundamentos teóricos (infra 2. y 3.) y metodológicos (infra 4.), para pasar luego a identificar algunos de los elementos sobre los que tiene que desarrollarse (infra 5. y 6.), así como a identificar algunas conclusiones (infra 7.).

\section{EL SISTEMA DEL DERECHO ADMINISTRATIVO EUROPEO}

\subsection{Concepto}

La noción de Derecho administrativo europeo puede emplearse para aludir a realidades diferentes. En esta contribución se utiliza específicamente para referirse al Derecho administrativo de la Unión Europea. Su objeto queda pues delimitado por dos criterios. El primero se refiere al origen de las normas que lo integran. En principio, se trata de normas y actos que forman parte del sistema jurídico de la Unión Europea, tanto del Derecho primario y secundario, como procedentes de la doctrina jurisprudencial del Tribunal de Justicia de la Unión Europea. Sin embargo, la peculiar naturaleza de la administración europea, que como se verá inmediatamente responde al tiempo a las notas de integración y apertura, conduce a que el Derecho administrativo europeo también incorpore razones jurídicas procedentes, respectivamente, de los Derechos internos de los Estados miembros y del Derecho internacional ${ }^{2}$. En definitiva, el Derecho administrativo europeo se entiende aquí como parte del Derecho de la Unión, sin perder de vista que este ordenamiento se abre a los Derechos nacionales, con los que queda integrado.

En segundo lugar, esas normas se caracterizan por su carácter administrativo. Esto último parece conjurar un viejo fantasma. Por un lado, debido a la peculiar evolución histórica de la Unión Europea, su Derecho administrativo difícilmente puede quedar delimitado por referencia a un determinado sujeto o institución ${ }^{3}$. Por otro lado, la integración de las funciones legislativa y ejecutiva y su atribución a varias instituciones, órganos y organismos de la Unión, de un lado, así como a los propios Estados miembros, de otro, priva de toda utilidad -si es que alguna vez la tuvo- a la definición construida a partir de un criterio negativo o residual ${ }^{4}$. Por este motivo no queda más remedio que acudir a criterios funcionales, pese a la indeterminación que inevitablemente presentan y, por tanto, a la incertidumbre que generan en la periferia de lo administrativo.

\footnotetext{
2 Herwig C. H. HOFMANN, Gerard C. ROWE y Alexander H. TÜRK, Administrative Law and Policy of the European Union, OUP, 2011, p. 907.

3 Eduardo GARCÍA DE ENTERRÍA y Tomás-Ramón FERNÁNDEZ, Curso de Derecho administrativo, vol. I, Thomson-Civitas, 2004, pp. 43-44.

${ }^{4}$ Harmut MAURER, Allgemeines Verwaltungsrecht, C. H. Beck, 2011, p. 3.
} 
Con estas cautelas, el Derecho administrativo europeo puede entenderse como el conjunto de principios y reglas del Derecho de la Unión Europea que regulan el ejercicio de las funciones administrativas para la implementación de las políticas de la Unión. El objeto de esas normas es la administración europea, entendida como una función cuyo ejercicio se puede concretar en la actuación de la Unión Europea, de los Estados miembros y de los sujetos privados con los que tanto la una como los otros entablan relaciones jurídicas 5 . La regulación del ejercicio de esas tareas por parte del Derecho administrativo europeo tiene lugar mediante dos estrategias complementarias. La primera consiste en la programación normativa de los aspectos sustantivos de la actividad en la que se concreta dicho ejercicio. La segunda es la regulación de las estructuras administrativas -organizativas, procedimentales y decisorias- a través de las cuales se acomete aquella actividad.

Así entendido, el Derecho administrativo europeo es un conjunto de normas sobre el que se proyecta una actividad teórica. Mientras que el primero constituye un sistema objetivo o real, la teoría del Derecho administrativo europeo es un sistema de conocimientos o, si se prefiere, un sistema científico en cierto sentido débil ${ }^{6}$. El desarrollo de la teoría del Derecho administrativo europeo se dirige a proporcionar un mejor conocimiento sobre su objeto, así como a lograr su progresivo perfeccionamiento. Lo primero conduce a la elaboración de proposiciones descriptivas -teorías positivas- acerca del Derecho administrativo europeo. Lo segundo se concreta en la elaboración de proposiciones prescriptivas - teorías normativas- sobre la producción, interpretación y aplicación de las normas que lo integran.

\subsection{Funciones}

El Derecho es un instrumento de dirección social que aspira a la eficacia, es decir, a ordenar efectivamente los procesos sociales sobre los que se proyecta. El Derecho administrativo europeo, en particular, es un instrumento de dirección y ordenación de los sujetos encargados de ejercer las tareas administrativas que comprenden la implementación de las políticas de la Unión Europea, así como de los procesos a través de los cuales esto se produce. Por este motivo, la teoría del Derecho administrativo europeo no puede limitarse a identificar los rasgos de los conceptos y técnicas jurídicas que incorporan sus normas, sino que ha de interrogarse acerca de los presupuestos necesarios para lograr su efectividad ${ }^{7}$.

Las afirmaciones anteriores tienen un carácter formal, en el sentido de que nada dicen acerca del contenido de las normas del Derecho administrativo europeo o, di-

\footnotetext{
5 Herwig C. H. HOFMANN, Gerard C. ROWE y Alexander H. TÜRK, Administrative Law and Policy of the European Union, OUP, 2011, p. 907.

6 Claus-Wilhelm CANARIS, Systemdenken und Systembegriff in der Jurisprudenz, Duncker \& Humblot, 1983, pp. 11-13.

7 Eberhard SCHMIDT-ASSMANN, Das Allgemeine Verwaltungsrecht als Ordnungsidee, Springer, 2006, pp. 18-19.
} 
cho en otros términos, del sentido en el que estas dirigen la actuación de la administración europea. Esta otra cuestión, relativa a sus funciones sustantivas, no se puede dilucidar en abstracto, sino a la vista del contenido de las normas que lo integran y de los impulsos que le dirigen sus presupuestos jurídico-políticos. La evolución del Derecho administrativo en los Estados europeos permite observar una tensión entre sus dos vocaciones históricas. La primera es la racionalización jurídica del ejercicio del poder mediante la limitación y la disciplina de la actuación administrativa. La segunda es la garantía de la eficacia de la administración y, con ella, de la efectividad de la tutela de los intereses públicos a los que esta sirve. Estas dos orientaciones finalistas constituyen la doble función del Derecho administrativo de los Estados europeos ${ }^{8}$. Aunque entre ellas no es posible establecer un orden de jerarquía abstracto, en cada sistema de Derecho administrativo -y aun dentro de cada uno de ellos a lo largo de las distintas fases de su evolución histórica- esa tensión se libera mediante puntos de equilibrio diversos en función de sus presupuestos constitucionales y políticos?

En lo que ahora interesa, la doble función del Derecho administrativo europeo es también racionalizar y garantizar la eficacia de la administración europea ${ }^{10}$. Lo primero consiste en limitar, ordenar y estructurar la implementación administrativa de las políticas europeas de conformidad con los principios constitucionales del Estado de Derecho, la democracia, la protección de los derechos fundamentales, la subsidiariedad y el equilibrio institucional. Lo segundo pasa por asegurar, no solo la efectividad del Derecho de la Unión, sino también la eficacia de la propia actuación de la administración europea que, como se verá, es un presupuesto constitucional del Derecho administrativo europeo ${ }^{11}$.

\subsection{Características}

La evolución histórica del Derecho administrativo europeo arranca del inicial reparto vertical del poder administrativo, en el que las esferas propias de las Comunidades Europeas y sus Estados miembros quedaban formalmente separadas. La progresiva ampliación y diversificación de las políticas europeas dio lugar sucesivamente al fortalecimiento de la administración directa de algunas de ellas, al incremento de relaciones horizontales entre las administraciones de los Estados y, en último término, a la generalización de una administración integrada que actúa mediante redes

8 Eberhard SCHMIDT-ASSMANN, Das Allgemeine Verwaltungsrecht als Ordnungsidee, Springer, 2006, pp. 16-18.

9 Carol HARLOW, Giacinto DELLA CANANEA, Päivi LEINO, "Introduction: European administrative law - a thematic approach”, en Carol HARLOW, Giacinto DELLA CANANEA y Päivi LEINO (eds.), Research Handbook on EU Administrative Law, Edward Elgar, 2017, p. 5.

10 Eberhard SCHMIDT-ASSMANN, "Verfassungsprinzipien für den Europäischen Verwaltungsverbund", en Wolfgang HOFFMANN-RIEM, Eberhard SCHMIDT-ASSMANN y Andreas VOSSKUHLE (Hrsg.), Grundlagen des Verwaltungsrechts, vol. I, C. H. Beck, 2006, p. 246.

11 Paul CRAIG, EU Administrative Law, OUP, 2018, pp. 274-276. 
administrativas en relación con todo el ciclo de las políticas públicas ${ }^{12}$. El resultado ha sido una ampliación del alcance del Derecho administrativo europeo, acompañado de una mayor fragmentación de su contenido. El Derecho administrativo europeo es cada vez menos homogéneo y se encuentra separado menos claramente de los Derechos administrativos de los Estados miembros ${ }^{13}$. Tal y como sucede en otros muchos casos, la apertura y movilidad del Derecho administrativo europeo -entendido como sistema objetivo o real- ha terminado ampliando su objeto a costa de reducir su unidad y coherencia interna. Asimismo, la mayor complejidad del sistema normativo dificulta el desarrollo de la teoría del Derecho administrativo europeo -es decir, del sistema científico-, tanto en relación con su adecuada comprensión, como en lo que se refiere a su posible reorientación a la vista de sus presupuestos políticos $\mathrm{y}$ constitucionales ${ }^{14}$. Buen ejemplo de ello es la evolución de las agencias europeas, que ha conducido a una cada vez mayor diversificación ${ }^{15}$, y con ello a una dificultad creciente de cara a la racionalización jurídica, tanto de su actividad, como de su control político y judicial ${ }^{16}$.

El resultado de ese proceso en el momento presente puede caracterizarse del modo siguiente $^{17}$. En primer lugar, la administración de las políticas de la Unión Europea tiene lugar a través de una pluralidad de actores, entre los que se cuentan las instituciones, órganos, organismos y agencias de la Unión, las autoridades de los Estados miembros, e incluso otras organizaciones internacionales y autoridades de terceros Estados. El Derecho administrativo de la Unión se abre así, por tanto, a los Derechos internos y aún al Derecho administrativo global ${ }^{18}$. En segundo lugar, la administración europea es una administración compuesta porque incorpora elementos propios de una administración centralizada, descentralizada y transnacional. Aunque no toda ella, buena parte de la actividad de la administración europea se desarrolla a través de procedimientos de cooperación y de redes administrativas que presentan grados variables -en ocasiones muy elevados- de integración. Algunas de estas estructuras para el ejercicio cooperativo o incluso conjunto de competencias administrativas se concretan en la creación de nuevos sujetos -integración subjetiva-, mientras que en otros casos la integración se produce mediante el diseño de procedimientos de toma

12 Herwig C. H. HOFMANN, "European administration: nature and developments of a legal and political space”, en Carol HARLOW, Giacinto DELLA CANANEA y Päivi LEINO (eds.), Research Handbook on EU Administrative Law, Edward Elgar, 2017, pp. 23-28.

13 Carol HARLOW, Giacinto DELLA CANANEA y Päivi LEINO, "Introduction: European administrative law - a thematic approach", en Carol HARLOW, Giacinto DELLA CANANEA y Päivi LEINO (eds.), Research Handbook on EU Administrative Law, Edward Elgar, 2017, pp. 2-3.

14 Patrick HILBERT, Systemdenken in Verwaltungsrecht und Verwaltungsrechtswissenschaft, Mohr Siebeck, 2015, pp. 219-223.

15 Merijn CHAMON, EU Agencies, OUP, 2016, pp. 45-46, 52-100.

16 Merijn CHAMON, EU Agencies, OUP, 2016, pp. 134-298, y 299-368.

17 Herwig C. H. HOFMANN, Gerard C. ROWE y Alexander H. TÜRK, Administrative Law and Policy of the European Union, OUP, 2011, pp. 908-911.

18 Paul CRAIG, UK, EU and Global Administrative Law, CUP, 2015 ; Herwig C. H. HOFMANN, Ellen VOS, Merijn CHAMON (eds.), The external dimension of EU agencies and bodies, Edgar Elgar, 2019. 
de decisiones -integración procedimental-. Con frecuencia las dos estrategias se desarrollan simultáneamente. En tercer lugar, en esas estructuras para la administración integrada europea, las relaciones de supraordenación entre gobierno y administración adquieren una relevancia menor que la que han tenido en las administraciones de los Estados europeos, caracterizadas históricamente por los principios de unidad y jerarquía. La mayor autonomía de las estructuras de la administración integrada europea con respecto a las instituciones de la Unión y los Estados miembros plantea importantes dificultades desde el punto de vista de sus fundamentos constitucionales. En cuarto lugar, la administración europea es particularmente inestable, por estar sujeta a un proceso de permanente transformación y por no haber quedado estabilizada normativamente, siquiera en sus aspectos esenciales, en el Derecho originario. En quinto lugar, la regulación de la administración europea de las diversas políticas sectoriales se caracteriza por un marcado pluralismo sectorial. De un lado, son pocas las reglas de aplicación transversal u horizontal a la administración europea. De otro lado, ni la doctrina académica ni la jurisprudencial han contribuido a ordenar de manera significativa esa realidad tan diversa.

\section{LA SISTEMATIZACIÓN DEL DERECHO ADMINISTRATIVO EUROPEO}

\subsection{Alcance y límites}

Los dos retos principales de la teoría del Derecho administrativo europeo son explicar y reorientar una realidad tan compleja como la descrita. Lo primero ha de procurar un mejor conocimiento del sistema objetivo. Lo segundo debe perseguir lograr una mejor satisfacción de sus presupuestos político-constitucionales. Las aportaciones más relevantes de la teoría del Derecho administrativo europeo han surgido para dar cuenta de alguna de las transformaciones más visibles que se han producido en esa evolución. Una de ellas ha sido la concepción de la administración europea como una administración multinivel ${ }^{19}$. Esta visión ha sido particularmente útil para explicar la alternativa entre ejecución centralizada y descentralizada del Derecho de la Unión Europea, así como las relaciones entre las autoridades de la Unión y las autoridades de los Estados miembros ${ }^{20}$. El concepto de administración mixta también ha permitido estudiar la gestión compartida de las tareas administrativas entre las autoridades europeas y nacionales ${ }^{21}$. Otra aportación relevante ha sido la noción de

19 Arthur BENZ, "European Public Administration as Multilevel Administration: A Conceptual Framework", en Michael W. BAUER y Jarle TRONDAL (eds.), The Palgrave Handbook on the European Administrative System, Palgrave Macmillan, 2015, pp. 31-47.

20 Giacinto DELLA CANANEA, "The European Administration: imperium and dominium”, en Carol HARLOW, Giacinto DELLA CANANEA y Päivi LEINO (eds.), Research Handbook on EU Administrative Law, Edward Elgar, 2017, pp. 64-65.

${ }^{21}$ Jacques ZILLER, "Les concepts d'administration directe, d'administration indirecte et de coadministration et les fondaments du droit administrative européen", en Jean-Bernard AUBY y Jacqueline 
espacio administrativo europeo ${ }^{22}$, que permite encapsular algunos elementos y rasgos propios de la administración europea -cooperación administrativa, actos transnacionales, intercambio de información, etc.- que no se dejan encerrar en la visión vertical y hasta cierto punto jerarquizada que encierra la teoría de la administración multini$\mathrm{vel}^{23}$. Una última construcción ha sido, en fin, la de la unión administrativa europea, concepto que procura reflejar la mayor complejidad que se deriva de la integración de elementos jerárquicos y cooperativos, de la mayor permeabilidad entre las esferas competenciales de las autoridades administrativas de la Unión y sus Estados, y de la creación de estructuras administrativas de ejecución compartida e integrada ${ }^{24}$. Estas aportaciones procuran racionalizar algunas de las propiedades más destacadas de la administración integrada europea, como son las redes administrativas, los procedimientos compuestos, o las cada vez más diversas y sofisticadas técnicas de cooperación interadministrativa y de gestión e intercambio de la información.

La de avanzar en el proceso de construcción sistemática del Derecho administrativo europeo no es, desde luego, una propuesta novedosa ${ }^{25}$. Tampoco puede negarse que haya habido importantes avances en tal sentido procedentes de la doctrina alemana $^{26}$, francesa ${ }^{27}$, italiana ${ }^{28}$ y espańola ${ }^{29}$. Sin embargo, en el momento presente

DUTHEIL DE LA ROCHÈRE (eds), Traité de Droit adminsitratif européen, Bruylant, 2014, pp. 327 334; Paul CRAIG, EU Administrative Law, OUP, 2018, pp. 30-34, 80-110.

22 Heinrich SIEDENTOPF y Benedikt SPEER, "L'espace administratif européen", en Jean-Bernard AUBY y Jacqueline DUTHEIL DE LA ROCHËRE (eds), . Traité de Droit adminsitratifeuropéen, Bruylant, 2014, pp. 451-465; Jarle TRONDAL y B. Guy PETERS, "A conceptual account of the European administrative space", en Michael W. BAUER y Jarle TRONDAL (eds.), The Palgrave Handbook on the European Administrative System, Palgrave Macmillan, 2015, pp. 79-92; Herwig C. H. HOFMANN, "European administration: nature and developments of a legal and political space", en Carol HARLOW, Giacinto DELLA CANANEA y Päivi LEINO (eds.), Research Handbook on EU Administrative Law, Edward Elgar, 2017, p. 21.

${ }^{23}$ Giacinto DELLA CANANEA, "The European Administration: imperium and dominium", en Carol HARLOW, Giacinto DELLA CANANEA y Päivi LEINO (eds.), Research Handbook on EU Administrative Law, Edward Elgar, 2017, p. 65.

24 Eberhard SCHMIDT-ASSMANN y Bettina SCHÖNDORF-HAUBOLD (Hrsg.), Der Europäische Verwaltungsverbund, Mohr Siebeck, 2015; Francisco VELASCO y Jens-Peter SCHNEIDER (eds.), La unión administrativa europea, Marcial Pons, 2008.

25 Eberhard SCHMIDT-ASSMANN, Das Allgemeine Verwaltungsrecht als Ordnungsidee, Springer, 2006, pp. 403-407.

26 Thomas VON DANWITZ, Verwaltungsrechtliches System und Europäische Integration, Mohr Siebeck, 1996; Eberhard SCHMIDT-ASSMANN, Das Allgemeine Verwaltungsrecht als Ordnungsidee, Springer, 2006, pp. 377-407; Jörg-Phillipp TERHECHTE (Hrsg.), Verwaltungsrecht der Europäischen Union, Nomos, 2011.

27 Jean-Bernard AUBY y Jacqueline DUTHEIL DE LA ROCHÈRE (eds.), Droit adminsitratif européen, Bruylant, 2014.

28 Mario P. CHITI y Guido GRECO, Trattato di diritto amministrativo europeo, Giuffrè, 2007; Mario P. CHITI, Diritto amministrativo europeo, Giuffrè, 2013; Giacinto DELLA CANANEA y Claudio FRANCHINI, I principi dell'amministrazione europea, Giappichelli, 2017.

29 Luciano PAREJO ALFONSO et al., Manual de derecho administrativo comunitario, CEURA, 2001; Francisco VELASCO y Jens-Peter SCHNEIDER (eds.), La unión administrativa europea, Marcial Pons, 2008; Jesús FUENTETAJA PASTOR, Derecho administrativo europeo, Civitas, 2016. 
todavía puede observarse un déficit relevante de sistematización del Derecho administrativo europeo. G. della Canena ha afirmado que una teoría del Derecho administrativo europeo que pretenda racionalizar la realidad contemporánea debe explorar mejor los fundamentos constitucionales contenidos en los Tratados, superar una visión del Derecho administrativo europeo exclusivamente centrada en el control judicial del ejercicio de la autoridad, así como emplear más extensamente el método comparado $^{30}$. Por su parte, H. C. H. Hofmann, G.C. Rowe y A. H. Türk han sostenido con buenas razones la necesidad de superar una situación de infradesarrollo teórico, avanzando en el proceso de sistematización jurídica de una realidad compleja que se caracteriza por tres rasgos generales: la unidad funcional vinculada al ejercicio de funciones administrativas para la implementación de políticas europeas, la separación formal de las respectivas esferas competenciales y la intensa cooperación procedimental entre las diversas autoridades que componen la administración integrada ${ }^{31}$.

El proceso de construcción sistemática no supone partir del presupuesto -evidentemente errado- de que el Derecho administrativo europeo -conforme a su contenido objetivo actual- es un sistema, sino precisamente de que no lo es, o, para ser más precisos, de que su objeto se aleja en gran medida de esa imagen abstracta porque la apertura, la movilidad y el pluralismo son en él particularmente acusados. El reto es, pues, partir de esa realidad y sobre ella desarrollar un pensamiento orientado a su sistematización, es decir, un proceso de construcción teórica dirigido a presentar y realizar el sistema ${ }^{32}$. Lo primero consiste en identificar los elementos del Derecho administrativo europeo que le aportan la medida de coherencia -orden-y de unidad de la que efectivamente disfruta. Lo segundo pasa por la permanente reforma del Derecho -el sistema objetivo- y la siempre inacabada reconstrucción de su marco teórico -el sistema científico- para incrementar el grado en el que se presentan aquellas propiedades.

\subsection{Justificación}

Por comparación con la simple descripción de las normas y las doctrinas que lo componen, la elaboración de una teoría del Derecho administrativo europeo orientada al sistema cumple cuatro funciones relevantes. Sin perjuicio de que en este contexto puedan presentar ciertas peculiaridades, esas funciones son las mismas que se han atribuido al pensamiento sistemático en el contexto del Derecho administrativo na-

30 Giacinto DELLA CANANEA, “The European Administration: imperium and dominium”, en Carol HARLOW, Giacinto DELLA CANANEA y Päivi LEINO (eds.), Research Handbook on EU Administrative Law, Edward Elgar, 2017, pp. 66-68.

31 Herwig C. H. HOFMANN, Gerard C. ROWE y Alexander H. TÜRK, Administrative Law and Policy of the European Union, OUP, 2011, pp. 911, y 936-938.

32 Claus-Wilhelm CANARIS, Systemdenken und Systembegriff in der Jurisprudenz, Duncker \& Humblot, 1983, pp. 16-18. 
cional ${ }^{33}$. La primera es la función de asistencia a la práctica administrativa y judicial: conceptos y doctrinas como los de "Decisión" o "reconocimiento mutuo" facilitan la aplicación del Derecho administrativo de la Unión por las autoridades administrativas y jurisdiccionales. Y ello no solo en los casos que responden a las características que los definen, donde esa aplicación se estandariza, sino también en aquellos otros que no lo hacen, en los que permiten una más precisa identificación de su singularidad. La segunda función es la asistencia a la política legislativa. El contraste entre las tipologías abstractas de procedimientos compuestos y los concretos procedimientos administrativos contemplados en el Derecho secundario permite identificar incoherencias, lagunas o, en general, aspectos necesitados de un más adecuado tratamiento normativo. La tercera función es la de mejorar la dogmática jurídica del Derecho administrativo europeo. Las doctrinas jurídicas elaboradas en relación con el Derecho sectorial se benefician de su orientación sistemática, es decir, mejoran si se construyen con la pretensión de mostrar la estructura, el fundamento y las relaciones recíprocas entre las diversas áreas que lo integran. Por último, la sistematización del Derecho administrativo europeo también facilita el desarrollo adecuado y funcional de sus relaciones con otros ordenamientos y, en particular, con el Derecho administrativo de los Estados miembros y con el Derecho administrativo global. La elaboración sistemática del primero permite apreciar mejor el alcance, los límites y las funciones de los conceptos y doctrinas que, teniendo en él su origen, van a incorporarse a esos otros ordenamientos. Y lo mismo sucede en el sentido opuesto: la sistematización del Derecho administrativo europeo permite identificar con mayor precisión el alcance de la influencia que recibe de ellos. Estas cuatro razones de la utilidad de contribuir a la presentación y realización del sistema son particularmente valiosas en el caso del Derecho administrativo europeo, por comparación con los Derechos administrativos de los Estados, debido a que, tal y como se ha indicado, la apertura, la movilidad y el pluralismo -es decir, su lejanía respecto del tipo ideal del sistema- son más acusados en el primero que en los segundos.

\subsection{Elementos}

La actividad de construcción sistemática se realiza mediante la identificación de un conjunto de principios, reglas, doctrinas y conceptos que contribuyen a ordenar el sistema real u objetivo, es decir, el Derecho administrativo europeo, alejándolo de la imagen de un conjunto de elementos meramente yuxtapuestos y desvinculados entre sí, para aproximarlo a los ideales regulativos del orden, la coherencia y la unidad. La teoría del Derecho administrativo europeo debe operar sobre esos elementos de dos maneras. La primera consiste en identificar los que efectivamente presenta el sistema normativo y que le dotan de su grado o medida de sistematización real. La

33 Eberhard SCHMIDT-ASSMANN, Das Allgemeine Verwaltungsrecht als Ordnungsidee, Springer, 2006, pp. 3-6. 
segunda consiste en proponer el desarrollo y la reorientación de esos elementos, al objeto de lograr una mayor aproximación.

Los elementos sobre los que descansa la sistematización del Derecho administrativo europeo pueden clasificarse en dos categorías. Una de ellas está formada por piezas que tienen carácter funcional y que, por tanto, se caracterizan por reducir a la unidad el sistema objetivo mediante la adecuación del contenido de las normas y actos que lo integran a sus fundamentos o exigencias sustantivas. La sistematización resulta aquí de la mayor o menor adecuación del contenido de las normas y actos del Derecho administrativo europeo a ciertas determinaciones sustantivas que él mismo proporciona. En relación con esta dimensión material del sistema, la misión de la teoría general es explicar en qué medida el Derecho administrativo europeo opera como un orden axiológico o teleológico por referencia a sus propios valores o fines, así como promover esa correspondencia mediante propuestas de reforma e interpretación jurídicas.

La segunda categoría está compuesta por elementos de carácter formal. Se trata de normas, doctrinas o conceptos que aportan la estructura sobre la que se construye el sistema. Estas piezas se corresponden con tipos abstractos de estructuras administrativas sometidos a reglas más o menos generales. Entre esas estructuras destacan los tipos de organización de las administraciones públicas, los procedimientos de toma de decisiones y las formas jurídicas que dan expresión a esa actividad. La teoría general del Derecho administrativo europeo tiene en estos tres ámbitos un enorme margen de desarrollo que pasa por clarificar, entre otras cuestiones, las relativas a los tipos de organización administrativa de las agencias europeas, la sistematización de los procedimientos administrativos compuestos, las modalidades de cooperación administrativa entre autoridades europeas y nacionales, la racionalización de la actividad normativa de la Comisión, o, en fin, la construcción de un régimen jurídico adecuado de las decisiones administrativas concretas de la administración europea.

\section{LA METODOLOGÍA DE LA SISTEMATIZACIÓN}

Forma y función son, pues, las dos vías por medio de las cuales se desarrolla simultáneamente la actividad de sistematización del Derecho administrativo europeo ${ }^{34}$. Antes de entrar a analizar los dos grupos de piezas con los que se desarrolla, conviene, sin embargo, referirse a sus presupuestos metodológicos. El Derecho administrativo europeo, entendido como sistema normativo o real, presenta grandes peculiaridades con respecto al Derecho administrativo propio del Estado constitucional. Aunque ello ha de tener consecuencias, necesariamente, en el contenido de su teoría general, es decir, en el producto que arroje la labor de su construcción sistemática, ésta última

34 Sobre las relaciones entre los pares sistema formal-material y sistema interno-externo, Patrick HILBERT, Systemdenken in Verwaltungsrecht und Verwaltungsrechtswissenschaft, Mohr Siebeck, 2015, pp. 48-62 y 63-108, en particular 60 . 
puede acometerse a través de una metodología semejante. Sin pretender ofrecer un programa cerrado, a continuación se describen tres estrategias metodológicas relevantes y complementarias.

\subsection{Deducción}

La primera de esas estrategias es la deducción de criterios a partir de los fundamentos o presupuestos normativos que condicionan el desarrollo y la aplicación del Derecho administrativo europeo. En el Derecho administrativo de los Estados constitucionales, esos presupuestos tienen su origen en las Constituciones, en las declaraciones de derechos, así como en los programas políticos más o menos generales que inspiran la política legislativa. Del Derecho constitucional interno -y del propio Derecho de la Unión Europea- no solo se derivan presupuestos de validez y aplicabilidad del Derecho administrativo nacional, sino también criterios relevantes para su construcción sistemática ${ }^{35}$.

En el ordenamiento supranacional, el Derecho primario cumple una función semejante: proporcionar criterios que estructuran y orientan el desarrollo de la teoría general del Derecho administrativo europeo ${ }^{36}$. Algunos de esos criterios tienen carácter sustantivo, como por ejemplo las distintas fuentes de legitimidad democrática contempladas en los Tratados (arts. 10 y 11 del Tratado de la Unión Europea), que permiten ordenar las fuentes y valorar críticamente el nivel de legitimidad de la administración europea en sus diversas formas. Otras, en cambio, tienen carácter formal, en el sentido de que se refieren a estructuras administrativas de esa naturaleza, como, por ejemplo, los procedimientos a través de las cuales se puede ejercer la potestad normativa derivada de la Comisión Europea ${ }^{37}$, los mecanismos para la gestión e intercambio de la información administrativa ${ }^{38}$, o el régimen jurídico de los actos administrativos de la Unión Europea ${ }^{39}$. Reducir el déficit de sistematización

35 Eberhard SCHMIDT-ASSMANN, Das Allgemeine Verwaltungsrecht als Ordnungsidee, Springer, 2006, pp. 43-45.

36 Eberhard SCHMIDT-ASSMANN, "Verfassungsprinzipien für den Europäischen Verwaltungsverbund", en Wolfgang HOFFMANN-RIEM, Eberhard SCHMIDT-ASSMANN y Andreas VOSSKUHLE (Hrsg.), Grundlagen des Verwaltungsrechts, vol. I, C. H. Beck, 2006, p. 248; Jörg-Phillipp TERHECHTE, "Einführung: Das Verwaltungsrecht der Europäischen Union als Gegenstand rechtswissenschaftlicher Forschung”, en Jörg-Phillipp TERHECHTE (Hrsg.), Verwaltungsrecht der Europäischen Union, Nomos, 2011, p. 59.

37 Herwig C. H. HOFMANN, Gerard C. ROWE y Alexander H. TÜRK, Administrative Law and Policy of the European Union, OUP, 2011, pp. 924-925; Paul CRAIG, EU Administrative Law, OUP, 2018, pp. 145-147.

38 Jens-Peter SCHNEIDER, "Information Exchange and its problems", en Carol HARLOW, Giacinto DELLA CANANEA y Päivi LEINO (eds.), Research Handbook on EU Administrative Law, Edward Elgar, 2017, pp. 81-112.

39 Xabier ARZOZ SANTISTEBAN, Concepto y régimen juridico del acto administrativo comunitario, IVAP, 1998; Oivier DUBOS y Marie GAUTIER, "Les actes communautaires d'exécution”, en 
del Derecho administrativo europeo exige proyectar esta metodología top-down en relación con unas y otras.

\subsection{Inducción}

La segunda estrategia se desarrolla en sentido opuesto y consiste en la inducción de reglas, estructuras y procesos de transformación más o menos relevantes a partir de las peculiaridades presentes en el Derecho administrativo sectorial ${ }^{40}$. El elemento clave en este proceso bottom-up es la idea de sector de referencia ${ }^{41}$. La teoría general del Derecho administrativo interno se ha desarrollado a partir de sectores de referencia en los que se observan problemas regulatorios característicos y se encuentran soluciones para los observados en otros ámbitos. La actualización y mejora de la teoría general requiere atender a la evolución del Derecho administrativo sectorial en aquellos ámbitos en los que los procesos de transformación son más relevantes por su capacidad para explicar y orientar el Derecho administrativo en el momento presente. Por su parte, los sectores de referencia proporcionan y reciben elementos del sistema, que se desarrolla así simultáneamente en ambos sentidos.

Esta aproximación metodológica se encuentra particularmente infradesarrollada en el caso del Derecho administrativo europeo. El estudio del régimen sectorial de la administración europea suele realizarse con la finalidad de comprender mejor y de resolver los problemas que presenta el Derecho administrativo en el concreto ámbito de que se trate. Ello es, claro está, necesario, pero no es suficiente. Son pocas las investigaciones en las que se pretende comparar el régimen jurídico aplicable a la administración europea en diversos ámbitos sectoriales ${ }^{42}$, y menos aún los estudios en los que ese análisis sectorial se acomete con vistas a desarrollar o revisar piezas de la teoría general del Derecho administrativo europeo, como pudieran ser, por ejemplo, las relativas a las formas jurídicas de expresión de la actuación de la administración europea ${ }^{43}$, o a las decisiones de adjudicación administrativa de recursos escasos ${ }^{44}$. El reciente libro de H. C. H. Hofmann, G.C. Rowe y A. H. Türk realiza una importante contribución desde esta perspectiva metodológica, al analizar los diferentes sectores

J.-B. AUBY y J. DUTHEIL DE LA ROCHÈRE (eds.), Traité deDroit adminsitratif européen, Bruylant, 2014, pp. 181-200; A. M. KEESEN, European Administrative Decisions, Europa Law Publishing, 2009.

40 Jörg-Phillipp TERHECHTE, „Einführung: Das Verwaltungsrecht der Europäischen Union als Gegenstand rechtswissenschaftlicher Forschung“, en Jörg-Phillipp TERHECHTE (Hrsg.), Verwaltungsrecht der Europäischen Union, Nomos, 2011, p. 79.

41 Eberhard SCHMIDT-ASSMANN, Das Allgemeine Verwaltungsrecht als Ordnungsidee, Springer, 2006, pp. 8-10.

${ }_{42}$ Jörg-Phillipp TERHECHTE (Hrsg.), Verwaltungsrecht der Europäischen Union, Nomos, 2011; Giacinto DELLA CANANEA y Martina CONTICELLI (eds.), I procedimenti amministrativi di 'adjudication' dell'Unione europea: principi generali e discipline settorali, Giappichelli, 2017.

43 Andreas GLASER, Die Entwicklung des Europäischen Verwaltungsrechts aus der Perspektive der Handlungsformenlehre, Mohr Siebeck, 2013.

44 Paul ADRIAANSE, Frank VAN OMMEREN, Willemine DEN OUDEN y Johan WOLSWINKEL (eds.), Scarcity and the State, Intersentia, 2016. 
del Derecho administrativo europeo a partir de una estructura estandarizada, con la finalidad de identificar rasgos y procesos de convergencia y diversidad regulatoria ${ }^{45}$.

\subsection{Apertura}

La tercera estrategia metodológica para el desarrollo de la teoría general del Derecho administrativo europeo es la apertura, que opera aquí en dos planos. El primero se refiere a la incorporación de otros saberes y metodologías. Si el Derecho administrativo europeo aspira a dirigir efectivamente los procesos sociales sobre los que se proyecta, su teoría general debe tratar de promover las condiciones necesarias para que ello resulte posible. Las redes administrativas, las agencias, los procedimientos compuestos, la gestión de la información administrativa, los tipos de actos jurídicos y el resto de elementos propios de la teoría general del Derecho administrativo son instrumentos de dirección cuya eficacia relativa puede ser valorada a la vista de las consecuencias que genera en cada caso su utilización. Esa valoración requiere analizar su comportamiento en el contexto más amplio en el que se despliegan, así como comparar su rendimiento con el de otros instrumentos alternativos. Por ese motivo, la teoría general del Derecho administrativo europeo no puede limitarse a utilizar los instrumentos tradicionales propios de la dogmática jurídica, sino que tiene que abrirse a otras ciencias sociales que le proporcionen metodologías adecuadas para ello como, por ejemplo, el análisis económico o los métodos empíricos. Su contribución a la mejora de la aplicación de ciertos sectores del Derecho administrativo europeo, como, por ejemplo, la prohibición de ayudas públicas, es evidente desde hace ya tiempo. Lo que quizás no haya sido tan claro es loa que esos métodos de investigación pueden aportar a un mejor desarrollo dogmático de las piezas de su teoría general.

Pero la apertura también caracteriza la metodología propia de la sistematización del Derecho administrativo europeo desde una segunda perspectiva, vinculada a los otros ordenamientos con los que se relaciona: los Derechos administrativos de los Estados miembros y el Derecho administrativo global. Por un lado, el desarrollo sistemático del Derecho administrativo europeo descansa en el análisis comparado de sus instituciones jurídicas ${ }^{46}$. A ello conduce el hecho de que el contenido de algunas de ellas - por ejemplo, los derechos fundamentales o el régimen de la responsabilidad patrimonial- esté definido normativamente por referencia a las tradiciones jurídicas nacionales o, en términos más generales, a los ordenamientos jurídicos de los Estados miembros. La vinculación entre el Derecho administrativo europeo y el desarrollo

\footnotetext{
45 Herwig C. H. HOFMANN, Gerard C. ROWE y Alexander H. TÜRK (eds.), Specialized Administrative Law of the European Union, OUP, 2018.

${ }^{46}$ Michel FROMONT, Droit administrative des Etats Européens, PUF, 2006; Giacinto DELLA CANANEA y Mario BUSSANI, “The 'Common Core' of Administrative Laws in Europe: A framework for Analysis", Maastricht Journal of European and Comparative Law, vol. 26, núm. 2, 2019, pp. 217-250.
} 
de un Derecho público común europeo también fortalece la apertura del primero a través del método comparado ${ }^{47}$. Por otro lado, la apertura de las relaciones entre el Derecho administrativo europeo, los ordenamientos nacionales de los Estados miembros y el propio Derecho administrativo global conduce a la incorporación en cada uno de ellos de razones jurídicas procedentes de los otros dos. El principio de reconocimiento mutuo ${ }^{48}$, los actos administrativos nacionales incorporados a procedimientos compuestos ascendentes ${ }^{49}$, o la incorporación al Derecho de la Unión de estándares aprobados por redes de reguladores globales ${ }^{50}$ son solo algunas manifestaciones de este tipo de apertura. Estos procesos de comunicación intersistemática se articulan a través de interfaces o dispositivos que deben ser diseñados teniendo en cuenta no solo las exigencias del sistema en el que se integran, sino también las del sistema con el que se produce la comunicación ${ }^{51}$. La necesidad de racionalizar el desarrollo de esos procesos de comunicación incide también, por tanto, en la construcción sistemática del Derecho administrativo europeo.

\section{LA FUNCIÓN EN EL SISTEMA DEL DERECHO ADMINISTRATIVO EUROPEO}

Tal y como se ha indicado, las herramientas de la construcción sistemática pueden ser de carácter funcional o estructural, según del modo en el que producen unidad y coherencia. En el primer grupo, la sistematización resulta de la adecuación -de intensidad variable- del contenido de las normas y actos que integran el Derecho administrativo europeo a ciertas determinaciones sustantivas que él mismo proporciona. En este ámbito, la misión de la doctrina académica es explicar en qué medida el Derecho administrativo europeo opera como un orden axiológico o teleológico por referencia a sus propios valores o fines, así como promover esa correspondencia mediante propuestas de reforma e interpretación de sus normas. Sin ánimo de proporcionar una clasificación exhaustiva, las piezas más relevantes de esta estrategia de sistematización son las siguientes.

\subsection{Presupuestos constitucionales}

En numerosos Estados miembros la principal fuente de unidad y coherencia de sus Derechos administrativos se encuentra en sus respectivas Constituciones. La vin-

\footnotetext{
47 Sabino CASSESE, Armin VON BOGDANDY y Peter HUBER (eds.), The Administrative State, OUP, 2017.

${ }_{48}$ Christine JANSSENS, The Principle of Mutual Recognition in EU Law, OUP, 2013; Luis ARROYO JIMÉNEZ y Adán NIETO MARTIIN (eds.), El reconocimiento mutuo en el Derecho español y europeo, Marcial Pons, 2018.

49 Sergio ALONSO DE LEÓN, Composite Administrative Procedures in the European Union, UCLM/Iustel, 2017.

50 Maurizia DE BELLIS, La regolazione dei mercati finanziari, Giuffe, Milano, 2012, pp. 301-398.

51 Luis ARROYO JIMÉNEZ, Empatía constitucional, Marcial Pons, 2016.
} 
culación constitucional del Derecho administrativo se concreta en un doble efecto: primero, las normas constitucionales operan como presupuestos de validez y de aplicabilidad del resto de las normas y actos que integran el ordenamiento administrativo -el sistema normativo-; y segundo, las decisiones constitucionales de carácter fundamental proporcionan impulsos y orientaciones de cara al desarrollo de su teoría general -el sistema científico-. Aunque no sea solo eso, el Derecho administrativo nacional es también, al menos en parte, Derecho constitucional concretizado ${ }^{52}$.

Una parte importante del grado de unidad y coherencia que caracteriza efectivamente al Derecho administrativo de los Estados miembros tiene su origen en que las normas y actos que lo integran están vinculados constitucionalmente. Y lo mismo puede decirse del Derecho administrativo europeo, cuya teoría general también debe esclarecer el papel que corresponde a sus bases o fundamentos constitucionales ${ }^{53}$. Sin embargo, en el contexto supranacional es preciso tener en cuenta dos peculiaridades relevantes. En relación con el primero de los efectos señalados, el material normativo que goza de la condición de lex superior y cuyo contenido, por tanto, opera como presupuesto o condición de validez de las normas y actos de Derecho administrativo secundario -y de aplicabilidad de las de Derecho interno- es mucho más extenso y detallado. Las normas contenidas en los Tratados arrojan la imagen de una Constitución muy densa que, además, no solo contiene decisiones relativas a la organización y la forma del poder, sino también al contenido de su acción. A lo cual hay que añadir el considerable volumen de principios y reglas que el Tribunal de Justicia ha configurado como principios generales del Derecho de la Unión o, más sencillamente, que ha adscrito a las disposiciones de los Tratados. Estas normas formalmente constitucionales y materialmente administrativas condicionan el desarrollo del resto del Derecho administrativo europeo.

Por lo que atañe al otro de los dos efectos señalados, el Derecho primario también proporciona impulsos y orientaciones para la sistematización del Derecho administrativo europeo. Sin embargo, no todas las normas de Derecho primario que condicionan la validez del Derecho administrativo secundario cumplen esta función sistematizadora. Se trata más bien de los valores, objetivos y principios generales que

52 La expresión es, como es conocido, de Fritz WERNER, "Verwaltungsrecht als konkretisiertes Verfassungsrecht", Deutsches Verwaltungsblatt, 1959, p. 527. Recientemente, Ferdinand WOLLENSCHLÄGER, "Verfassung im Allgemeinem Verwaltungsrecht: Bedeutungsverlust durch Europäisierung und Emanzipation?", Veröffentlichungen der Vereinigung der Deutschen Staatsrechtslehrer, núm. 75, 2016, pp. 199-200; Sabino CASSESE, "La costituzionalizzazione del diritto amministrativo", Scritti in onore di Gaetano Silvestri, Giappichelli, 2016, pp. 501 y ss.; Luc HEUSCHLING, "The Complex Relationship Between Administrative and Constitutional Law: A Comparative and Historical Analysis", en Armin VON BOGDANDY, Peter HUBER y Sabino CASSESE (eds.), The Administrative State, OUP, 2017, pp. 493-556; Luis ARROYO JIMÉNEZ, "Derecho administrativo y Constitución Española", Revista de Administración Pública, núm. 209, 2019, pp. 145-174.

53 Eberhard SCHMIDT-ASSMANN, "Verfassungsprinzipien für den Europäischen Verwaltungsverbund", en Wolfgang HOFFMANN-RIEM, Eberhard SCHMIDT-ASSMANN y Andreas VOSSKUHLE (Hrsg.), Grundlagen des Verwaltungsrechts, vol. I, C. H. Beck, 2006, pp. 243-246; Matthias RUFFERT, "The constitutional basis of EU administrative law", en Susan ROSE-ACKERMAN y Peter LINDSETH (eds.), Comparative Administrative Law, Edward Elgar, 2017, pp. 667-679. 
expresan las decisiones fundamentales en relación con la configuración del poder de la Unión. Esas bases constitucionales del Derecho administrativo europeo pueden ordenarse en tres grupos ${ }^{54}$.

El primero es el de los valores de la Unión consagrados en el art. 2 del Tratado de la Unión Europea, entre los que aparecen los principios constitucionales estructurales que recogen la herencia europea del Estado constitucional: la democracia, el Estado de Derecho, la protección de los derechos fundamentales y la solidaridad. Se trata de principios de contenido muy general que comprenden exigencias más concretas. Algunas de esas exigencias están especificadas en el propio art. 2. Es el caso, por ejemplo, de la libertad y la no discriminación, que al tiempo que constituyen derechos fundamentales son exigencias vinculadas a una concepción sustantiva del Estado de Derecho que, aunque discutida en la tradición del common law ${ }^{55}$, es generalmente aceptada en el continente europeo ${ }^{56}$. Otras son proclamadas en la Carta de los Derechos Fundamentales de la Unión Europea o en diversos preceptos de los Tratados - por ejemplo, las diferentes dimensiones de la democracia relacionadas con la representación política, la participación y el pluralismo, reconocidas en los arts. 10 y 11 del Tratado de la Unión Europea-, mientras que otras, en fin, son proclamadas como principios generales del Derecho de la Unión por el Tribunal de Justicia de la Unión Europea ${ }^{57}$, bien directamente -por ejemplo, los principios de eficacia ${ }^{58}$ y equivalencia ${ }^{59}-$, o bien a través de su adscripción a los anteriores - por ejemplo, la protección de la confianza legítima ${ }^{60}$ o el principio de proporcionalidad ${ }^{61}$.

54 Eberhard SCHMIDT-ASSMANN, "Verfassungsprinzipien für den Europäischen Verwaltungsverbund", en Wolfgang HOFFMANN-RIEM, Eberhard SCHMIDT-ASSMANN y Andreas VOSSKUHLE (Hrsg.), Grundlagen des Verwaltungsrechts, vol. I, C. H. Beck, 2006, pp. 248-250; Armin VON BOGDANDY, "Constitutional Principles", en Armin VON BOGDANDY y Jürgen BAST (eds.), Principles of European Constitutional Law, Hart, 2015, pp. 3-12.

55 John TASIOULAS, "The rule of law", en John TASIOULAS (ed.), The Cambridge Companion to the Philosophy of Law, CUP, 2019 en prensa (original disponible en: https://papers.ssrn.com/sol3/ papers.cfm?abstract_id=3216796); Cass R. SUNSTEIN y Adrian VERMEULE, "The Morality of Administrative Law”, Harvard Law Review, núm. 131, 2018, pp. 1924-1978.

56 Elías DÍAZ, Estado de Derecho y sociedad democrática, Cuadernos para el Diálogo, 1966, p. 29; K. HESSE, Grundzüge des Verfassungsrechts der Bundesrepublik Deutschland, C.H. Beck, 1988, pp. 78-79; Luc HEUSCHLING, État de droit, Rechtsstaat, Rule of Law, Dalloz, 2002, p. 28; Marcus KLAMERT y Dimitri KOCHENOV, “Article 2”, en Manuel KELLERBAUER, Marcus KLAMERT y Jonathan TOMKIN (eds.), The EU Treaties and the Charter of Fundamental Rights. A Commentary, OUP, 2019, p. 28; Paul CRAIG, EU Administrative Law, OUP, 2018, p. 269.

57 Takis TRIDIMAS, The General Principles of EU Law, OUP, 2006; Xavier GROUSSOT, General Principles of Community Law, Europa Law Publishing, 2006; Paul CRAIG, EU Administrative Law, OUP, 2018, pp. 268-276.

58 Asunto C-6 y 9/90, Francovich y Bonifaci c Italia, ECLI:EU:C:1991:428.

59 Asunto 33/76, Rewe-Zentralfinanz, ECLI:EU:C:1976:188.

60 Asuntos 7/56 y 3-7/57, Algera c. Common Assembly, ECLI:EU:C:1957:7; 42 y $49 / 59$ SNUPAT c. Alta Autoridad, ECLI:EU:C:1961:5; 14/61, Hoogovens v Alta Autoridad, ECLI:EU:C:1962:28; 14/181 Alpha Steel c Comisión, ECLI:EU:C:1982:76; y 12/85 Consorzio Cooperative d'Abruzzo c. Comisión, ECLI:EU:C:1987:111.

61 Asuntos 8/55, Fédération charbonnier de Belgique c. Alta Autoridad, ECLI:EU:C:1956:11; 11/70, Internationale Handelsgesellschaf, ECLI:EU:C:1970:114. 
El segundo grupo de fundamentos constitucionales del Derecho administrativo europeo está formado por directrices que imponen fines a las autoridades encargadas de la producción y aplicación de las normas que lo componen. Entre ellos se encuentran los definidos en el artículo 3 del Tratado de la Unión Europea -el mantenimiento del mercado interior, la garantía de una economía social de mercado, la lucha contra la exclusión social, la protección de la diversidad cultural, etc. -, así como los objetivos más concretos a los que otras normas de los Tratados vinculan el ejercicio de las competencias de la Unión -la garantía de un nivel de vida equitativo a la población agrícola, la lucha contra el cambio climático, la seguridad del abastecimiento energético, etc.-. Estas determinaciones finalistas ordenan el desarrollo ulterior del Derecho administrativo europeo y, por tanto, contribuyen a incrementar su grado de unidad y coherencia, tanto en lo que respecta a la actividad legislativa, pues es bien sabido que la elección de la base jurídica debe basarse en elementos objetivos susceptibles de control jurisdiccional entre los que figuran, en particular, el objetivo y el contenido del acto ${ }^{62}$, como en lo que se refiere a la interpretación de las normas correspondientes mediante la construcción de argumentos relacionados con su espíritu y finalidad ${ }^{63}$.

La tercera clase de presupuestos constitucionales del Derecho administrativo europeo es la de los principios que configuran la organización del ejercicio del poder administrativo, tanto los que gobiernan el reparto del poder entre los Estados y la Unión, como entre las diversas instituciones, órganos, organismos y agencias que forman parte de la segunda -atribución, subsidiariedad, proporcionalidad, equilibrio institucional, cooperación leal, etc.-. Las dos variantes inciden intensamente en la configuración de la administración europea. Por un lado, el Derecho primario ofrece las bases constitucionales del modelo de implementación nacional de la ejecución administrativa de las políticas europeas (arts. 291 y 197 del Tratado de Funcionamiento), así como de la administración directa a través de instituciones, órganos, organismos y agencias de la Unión (arts. 17, 290, 291 y 298 del Tratado de Funcionamiento). Por otro lado, las disposiciones de los Tratados y la doctrina jurisprudencial del Tribunal de Justicia también limitan y orientan la configuración de la administración supranacional europea a través de sus diferentes actores. El espacio de mejora que tiene ante sí el Tribunal de Justicia es considerable y comprende, por ejemplo, la revisión de la doctrina sobre la delimitación de los actos delegados y de ejecución (arts. 290 y 291 del Tratado de Funcionamiento) ${ }^{64}$, o de la relativa a los límites de los poderes que pueden atribuirse a las agencias ${ }^{65}$.

${ }^{62}$ Asunto 45/86, Comisión c. Consejo, ECLI:EU:C:1987:163; C-300/89, Comisión c. Consejo, ECLI:EU:C:1991:244.

63 Asuntos 26/62, Van Gend \& Loos ECLI:EU:C:1963:1; C-127/00, Hässle AB, ECLI:EU:C:2003:661, para. 55; Conclusiones del AG Pedro Cruz Villalón en el asunto C314/12, UPC Telekabel Wien GmbH, ECLI:EU:C:2013:781, paras. 55 y ss.

64 Asuntos 427/12, Comisión c. Parlamento Europeo y Consejo, ECLI:EU:C:2014:170; 88/14 Comisión c. Parlamento Europeo y Consejo, ECLI:EU:C:2015:499. Paul CRAIG, EU Administrative Law, OUP, 2018, pp. 141-147.

65 Asuntos 9/56, Meroni c Alta Autoridad, ECLI:EU:C:1958:4; y C-270/12, Reino Unido c. Parlamento Europeo y Consejo, ECLI:EU:C:2014:18. Merijn CHAMON, EU Agencies, OUP, 2016, pp. 175-249; Paul CRAIG, EU Administrative Law, OUP, 2018, pp. 168-172. 


\subsection{Dirección legislativa}

Buena parte de los principios constitucionales señalados se imponen directamente a la administración europea, cuya organización y funcionamiento se encuentran así parcialmente determinados desde el Derecho primario. Sin embargo, dentro del marco definido por este último, las instituciones de la Unión gozan de un extenso margen de libre configuración para la concreción normativa de los fines y para la elección de los instrumentos de las diversas políticas europeas. Las instituciones que intervienen en los procedimientos legislativos tienen la capacidad -más o menos amplia, según los casos- de configurar las tareas administrativas propias de cada política pública, así como las estructuras administrativas encargadas de su realización. $\mathrm{Al}$ igual que en el marco de los Estados miembros la ley parlamentaria dirige la actuación de las administraciones nacionales ${ }^{66}$, también en el contexto supranacional europeo la actividad legislativa de las instituciones contribuye a dirigir el desarrollo de la actuación de la administración europea ${ }^{67}$.

En lo que ahora interesa, las normas y actos legislativos a través de los cuales se acomete esa labor de dirección concretan los fines del Derecho administrativo europeo sectorial y, con ello, fortalecen los elementos materiales o funcionales del sistema. $\mathrm{Al}$ igual que sucede en el marco de las relaciones entre el Derecho primario y el Derecho secundario, las normas y actos legislativos incrementan la unidad y coherencia de las normas y actos no legislativos. Y lo hacen operando tanto en el plano de su producción, como en el de su interpretación administrativa y jurisdiccional. En efecto, al precisar el contenido de esos fines, los actos legislativos facilitan la interpretación del resto del Derecho secundario mediante argumentos sistemáticos y teleológicos, que son las vías características a través de las cuales un ordenamiento puede ver incrementado sus niveles de coherencia y unidad según elementos funcionales. La medida concreta en la que el Derecho administrativo europeo se asemeje, en cada sector de actuación de la administración europea, al ideal del sistema, depende, en un grado elevado, de que su dirección legislativa le imponga fines bien definidos, una tendencia esta que puede advertirse en la reciente evolución del Derecho secundario ${ }^{68}$.

\subsection{Discrecionalidad}

Durante los últimos ańos se ha puesto de manifiesto que el Derecho administrativo europeo presenta carencias importantes a la hora de racionalizar jurídicamente

66 Franz REIMER, “Das Parlamentsgesetz als Steuerungsmittel und Kontrollmasstab”, en Wolfgang HOFFMANN-RIEM, Eberhard SCHMIDT-ASSMANN y Andreas VOSSKUHLE (Hrsg.), Grundlagen des Verwaltungsrechts, vol. I, C. H. Beck, 2006, p. 535.

67 Herwig C. H. HOFMANN, Gerard C. ROWE y Alexander H. TÜRK, Administrative Law and Policy of the European Union, OUP, 2011, pp. 94-97; Paul CRAIG, EU Administrative Law, OUP, 2018, pp. 111-113.

${ }^{68}$ Herwig C. H. HOFMANN, Gerard C. ROWE y Alexander H. TÜRK (eds.), Specialized Administrative Law of the European Union, OUP, 2018, pp. 638-640. 
la discrecionalidad, esto es, los poderes atribuidos a la administración por medio del Derecho para concretar la regla que determina el contenido de la decisión administrativa ${ }^{69}$. Por un lado, la crisis financiera y los ajustes institucionales a los que ha dado lugar han extendido de manera considerable los poderes discrecionales de las instituciones, órganos, organismos y agencias de la Unión ${ }^{70}$. Por otro lado, en lugar de reconocer y garantizar el ejercicio racional y transparente de poderes discrecionales por parte de las agencias, el Derecho administrativo europeo parece querer disimular la naturaleza discrecional de esas prerrogativas, sobre todo cuando no es la Comisión o el Banco Central Europeo quien las detenta ${ }^{71}$, en una tendencia probablemente causada por la doctrina jurisprudencial que limita la posibilidad de atribuir poderes discrecionales a las agencias de la Unión Europea, a la que se acaba de hacer referencia ${ }^{72}$.

El tratamiento de la discrecionalidad de la administración europea por parte de la doctrina académica, así como de la propia jurisprudencia del Tribunal de Justicia, ha sido hasta ahora muy poco refinado analíticamente, se ha desarrollado a espaldas de sus presupuestos constitucionales y, además, ha tenido un carácter casi exclusivamente sectorial. Sólo recientemente se está avanzando en este campo mediante la superación de una visión de la discrecionalidad administrativa atomizada y centrada exclusivamente en su control judicial, para abordarla desde su posición en el sistema del Derecho administrativo europeo ${ }^{73}$. Los elementos formales del sistema a los que más tarde aludiré -especialmente las estructuras organizativas y procedimentalesson particularmente relevantes a la hora de comprender y mejorar el ejercicio de los poderes discrecionales de la administración europea ${ }^{74}$.

Por su parte, el papel de los elementos funcionales no solo alcanza al ejercicio de la discrecionalidad, sino también - de forma muy destacada- a su atribución nor-

69 Joana MENDES, "Executive Discretion in the EU: Between National Traditions and EU Law", en J. MENDES (ed.), EU Executive Discretion and the Limits of Law, OUP, 2019, p. 5; M. BACIGALUPO, La discrecionalidad administrativa (estructura normativa, control judicial y limites constitucionales a su atribución), Marcial Pons, 1997; J. M. RODRÍGUEZ DE SANTIAGO, Metodología del Derecho administrativo, Marcial Pons, 2016.

${ }^{70}$ Joana MENDES, "Executive Discretion in the EU: Between National Traditions and EU Law", en J. MENDES (ed.), EU Executive Discretion and the Limits of Law, OUP, 2019, pp. 3-4.

71 Eduardo CHITI, "Is EU Administrative Law Failing in some of Its Crucial Tasks?", European Law Journal, vol. 22, núm. 5, 2016, pp. 588-590.

72 Véase. supra, nota 65.

73 Roberto CARANTA, "On discretion”, en Sacha PRECHAL y Bert VAN ROERMUND (eds.), The Coherence of EU law, OUP, 2008, pp. 181-215; Aude BOUVERESSE, Le pouvoir discrétionnaire dans l'ordre juridique communautaire, Bruylant, 2010; Joana MENDES, "Discretion, Care, and Public Interest in the EU Administration: Probing the Limits of the Law”, Common Market Law Review, núm. 53, 2016, pp. 419 y ss.; Joana MENDES, "Bounded Discretion in EU Law: A Limited Judicial Paradigm in a Changing EU”, Modern Law Review, núm. 80, 2017, pp. 443-472; Joana MENDES (ed.), EU Executive Discretion and the Limits of Law, OUP, 2019; Mattias WENDEL, Verwaltungsermessen als Mehrebenenproblem, Mohr Siebeck, 2019.

74 Joana MENDES, "Discretion, Care, and Public Interest in the EU Administration: Probing the Limits of the Law", Common Market Law Review, núm. 53, 2016, pp. 419-452. 
mativa y su posterior control jurisdiccional. Y ello en un doble sentido. En primer lugar, los principios constitucionales del Derecho administrativo de carácter estructural proporcionan los fundamentos para racionalizar la atribución, el ejercicio y el control de las potestades discrecionales de la administración europea. Entre ellos han de ocupar una posición destacada los principios de legalidad, control judicial, legitimidad democrática y eficacia de la acción administrativa. Su función es proporcionar criterios normativos que justifiquen tipos y grados variables de discrecionalidad administrativa y de control judicial. Este análisis deductivo ha de completarse con estudios que proporcionen, por inducción, pautas más o menos reconocibles en la legislación y en la jurisprudencia sectoriales ${ }^{75}$. Contrastar los primeros con las segundas nos puede proporcionar un mejor conocimiento del funcionamiento real de la discrecionalidad de la administración europea, así como herramientas útiles para su perfeccionamiento.

En segundo lugar, las directrices constitucionales y los fines elegidos por las normas y actos legislativos contribuyen, tal y como se ha indicado, al incremento de la unidad y coherencia de la administración europea y de su Derecho. Sin embargo, la importancia de esa contribución no es siempre la misma. El contenido de la actuación administrativa está a veces determinado muy intensamente a través de programas normativos condicionales. Pero la administración europea también actúa en ámbitos cuya regulación le atribuye poderes discrecionales. En estos casos, el Derecho europeo no renuncia a dirigir la actuación administrativa, sino que lo hace a través de programas normativos finales que resultan, bien de los principios constitucionales pertenecientes a los dos primeros bloques identificados, o bien de los fines impuestos por el legislador europeo en relación con la concreta política de que se trate. La administración europea goza aquí de un margen, también de variable intensidad en función del ámbito material en cuestión, para la selección autónoma del contenido de cada una de las medidas en las que se concreta la definición e implementación de esas políticas. Sin embargo, las normas primarias y secundarias que le imponen la obligación de perseguir determinados fines limitan el alcance de la discrecionalidad otorgada, condicionan su ejercicio por la administración y facilitan su control jurisdiccional. En definitiva, la contribución de los elementos sustantivos a la sistematización del Derecho administrativo europeo es tanto mayor cuanto más extensos sean los poderes discrecionales con los que cuente la administración europea.

En un trabajo reciente que permite ilustrar esta idea, J. Mendes ha argumentado convincentemente que el ejercicio y el control de la discrecionalidad pueden mejorarse prestando más atención a las normas que imponen a la administración europea la obligación de proteger determinados intereses públicos, es decir, a las que incorporan programas finales. Frente a la doctrina jurisprudencial del Tribunal de Justicia de la Unión Europea, que pretende apurar el control judicial atendiendo exclusivamente a la apreciación de los hechos determinantes de las decisiones administrativas, el

75 Herwig C. H. HOFMANN, Gerard C. ROWE y Alexander H. TÜRK (eds.), Specialized Administrative Law of the European Union, OUP, 2018, pp. 638-640. 
principio de objetividad, o de cuidado debido, permitiría diseñar un control judicial de la discrecionalidad administrativa que no sólo asegure la corrección técnica de las apreciaciones fácticas ${ }^{76}$, sino también la adecuada composición de los intereses públicos cuya tutela el Derecho impone a la administración europea. Una decisión discrecional válida tiene que descansar en una apreciación razonable de las circunstancias fácticas relevantes, así como en una ponderación equilibrada de los valores, principios y fines que el Derecho de la Unión impone a la administración europea y que justifican la atribución de un poder discrecional ${ }^{77}$.

\section{LA FORMA EN EL SISTEMA DEL DERECHO ADMINISTRATIVO EUROPEO}

La sistematización del Derecho administrativo europeo también descansa en elementos de carácter formal. Estas piezas dotan a las normas que lo integran -caracterizadas, como están, por el pluralismo y la fragmentación- de una cierta estructura, incrementando con ello su grado de unidad y coherencia, pero ahora por referencia a tipos de organizaciones burocráticas, de procedimientos administrativos y de formas jurídicas para la expresión de la actuación de la administración europea. El margen de mejora que ofrecen al Derecho administrativo europeo es particularmente amplio ${ }^{78}$.

\subsection{Organización}

Las estructuras organizativas del Derecho administrativo europeo presentan algunos problemas que han sido ya correctamente diagnosticados. En primer lugar, las formas de organización jurídica de la administración de la Unión Europea son muy heterogéneas ${ }^{79}$. Por un lado, las modalidades de organización administrativa no han hecho sino crecer y diversificarse durante los últimos tiempos. Por otro lado, su utilización por parte de la legislación secundaria es francamente desordenada y no parece responder a criterios homogéneos, sino más bien a preferencias de carácter puramente sectorial. En segundo lugar, aunque desde un punto de vista formal sigue siendo siempre posible atribuir las decisiones administrativas, bien a una organización su-

76 Herwig C. H. HOFMANN, "Interdependencies between Delegation, Discretion and the Duty of Care Regarding Facts", en Joana MENDES (ed.), EU Executive Discretion and the Limits of Law, OUP, 2019, pp. 230-235.

77 Joana MENDES, "Discretion, Care, and Public Interest in the EU Administration: Probing the Limits of the Law", Common Market Law Review, núm. 53, 2016, pp. 419-452.

78 Andreas VON ARNAULD, “Zum Status quo des europäischen Verwaltungsrechts", en Jörg Philipp TERHECHTE (Hrsg.), Verwaltungsrecht der Europäischen Union, Nomos, 2011, pp. 122-123.

${ }_{79}$ Herwig C. H. HOFMANN, "European administration: nature and developments of a legal and political space”, en Carol HARLOW, Giacinto DELLA CANANEA y Päivi LEINO (eds.), Research Handbook on EU Administrative Law, Edward Elgar, 2017, pp. 28-33; Herwig C. H. HOFMANN, Gerard C. ROWE y Alexander H. TÜRK, Administrative Law and Policy of the European Union, OUP, 2011, pp. 623-629. 
pranacional, o bien a una autoridad nacional -con las correspondientes consecuencias en relación con su control político y judicial ${ }^{80}$-, el grado de integración que caracteriza a las redes a través de las cuales se desarrolla la administración europea es muy elevado, especialmente en algunos ámbitos materiales. Las redes administrativas europeas se caracterizan simultáneamente, en efecto, por la separación formal entre autoridades europeas y nacionales y por el ejercicio conjunto de las tareas administrativas ${ }^{81}$. En tercer lugar, esta situación conduce a déficits dirección y de rendición de cuentas y, por tanto, a la reducción de la legitimidad efectiva de la administración europea ${ }^{82}$. Por una parte, no hay cauces bien definidos para la transmisión de directrices políticas hacia las estructuras administrativas. Por otro lado, el ejercicio integrado de tareas administrativas y la falta de transparencia y claridad acerca de quién hace qué dificultan la rendición de cuentas y el funcionamiento ordinario de los mecanismos de control político de la actuación administrativa. Finalmente, la estricta separación del ámbito jurisdiccional de los tribunales nacionales y europeos reduce la eficacia del control judicial del ejercicio integrado de tareas administrativas a través de redes europeas.

Algunos de estos problemas no podrán resolverse sin acometer profundas reformas en la arquitectura institucional de la Unión Europea que reconecten las vías de legitimación del poder con las fórmulas a través de las cuales éste se ejerce realmente. En otros casos podrían llegar a ser suficientes reformas puntuales en el Derecho secundario, tanto de carácter sectorial como horizontal. Con independencia de ello, la sistematización del Derecho administrativo europeo, entendida como un proyecto académico vinculado al desarrollo de su teoría general, puede contribuir a reducir el alcance de esas debilidades, así como a mejorar las propuestas de regulación de las fórmulas organizativas de la administración europea.

Esa agenda de investigación debería comprender, entre otras, las dos tareas siguientes. Ante todo, es preciso mejorar la clasificación de los tipos abstractos de organización administrativa presentes en el espacio administrativo europeo -desde la organización centralizada en la Comisión, hasta las diversas clases de agencias, pasando por los diferentes tipos de redes de cooperación-, a la vista de, al menos, tres criterios: primero, sus características formales como organización -personificación jurídica, capacidad de obrar, autonomía presupuestaria, órganos de gobierno, etc.-; segundo, su papel en el marco de relaciones de dirección -sometimiento a instrucciones procedentes de las instituciones y a recursos ante otros actores, estructura interna jerárquica, incorporación de expertos designados por otras autoridades, etc.-; y tercero, la presencia de técnicas de cooperación administrativa -intercambio

\footnotetext{
${ }^{80}$ Véase, no obstante, asuntos C-202 y 238/28, Ilmārs Rimševiččs y BCE c. República de Letonia, ECLI:EU:C:2019:139.

${ }^{81}$ Herwig C. H. HOFMANN, Gerard C. ROWE y Alexander H. TÜRK, Administrative Law and Policy of the European Union, OUP, 2011, pp. 921-922.

82 Herwig C. H. HOFMANN, Gerard C. ROWE y Alexander H. TÜRK, Administrative Law and Policy of the European Union, OUP, 2011, pp. 928-938.
} 
de información, acuerdos administrativos, apertura a redes de actores globales, etc.-, tanto en su interior, como en sus relaciones con otros sujetos.

La finalidad de este esfuerzo no es simplemente describir las diferentes formas que puede presentar la organización administrativa europea, sino identificar las piezas con las que está construida esa realidad diversa ${ }^{83}$. Esa labor tiene que desarrollarse mediante dos estrategias. En primer lugar, el análisis sectorial debe responder a la pregunta de hasta qué punto aparecen pautas regulatorias comunes en ámbitos materiales más o menos próximos u homogéneos. Los escasos trabajos realizados hasta ahora en este terreno no parecen sugerir que así sea ${ }^{84}$. En segundo lugar, es preciso obtener, ahora por vía deductiva, criterios más o menos generales relativos a las exigencias que las bases constitucionales del Derecho administrativo europeo imponen a las estructuras organizativas en un doble terreno: por un lado, el relativo al carácter multinivel -0 , si se prefiere-federal de la administración europea, del que resultan orientaciones y límites para la configuración de las redes administrativas integradas por representantes de las autoridades europea y nacionales; $y$, por otro, el del reparto interno del poder, condicionado por las exigencias de legitimidad que resultan de los principios de democracia, eficacia y Estado de Derecho ${ }^{85}$. Un riesgo cierto es trasladar acríticamente doctrinas procedentes del Derecho constitucional de los Estados miembros, donde desempeñan una función de legitimación del poder administrativo a la vista del concreto sistema institucional interno, sin tener en cuenta que el sistema institucional de la Unión Europea presenta importantes peculiaridades.

La segunda tarea de una teoría general del Derecho administrativo debería ser explorar, ahora desde un punto de vista normativo, si es o no posible identificar ámbitos materiales de la administración europea en los que, por tener un contenido o unas características relevantes más o menos homogéneas -administración de riesgos, prestación de servicios, gestión de programas de gasto, supervisión del mercado, etc.-, ciertos tipos de organización administrativa -agencias independientes, agencias infraordenadas a la Comisión, comités de expertos nacionales dentro y fuera del procedimiento de comitología, órganos integrados por expertos nombrados por la Comisión, etc.-, pudieran ser prima facie más adecuados que otros a la vista de las exigencias constitucionales que se han señalado. El papel de la teoría general del Derecho administrativo no es, claro está, encontrar en sus bases constitucionales la fórmula organizativa óptima para cada ámbito material de la administración europea -algo que corresponde al ámbito de la acción política-, sino, más prudentemente,

${ }^{83}$ Herwig C. H. HOFMANN, Gerard C. ROWE y Alexander H. TÜRK (eds.), Specialized Administrative Law of the European Union, OUP, 2018, p. 628.

${ }^{84}$ Herwig C. H. HOFMANN, Gerard C. ROWE y Alexander H. TÜRK (eds.), Specialized Administrative Law of the European Union, OUP, 2018, pp. 623-629.

85 Herwig C. H. HOFMANN, "European administration: nature and developments of a legal and political space", en Carol HARLOW, Giacinto DELLA CANANEA y Päivi LEINO (eds.), Research Handbook on EU Administrative Law, Edward Elgar, 2017, pp. 41-42; Herwig C. H. HOFMANN, Gerard C. ROWE y Alexander H. TÜRK (eds.), Administrative Law and Policy of the European Union, OUP, 2011, pp. 911-912, pp. 915-916. 
sugerir criterios que ordenen la deliberación acerca del diseño institucional. No se trata, pues, de sustituir la experimentación por el sistema, sino de mejorar aquella a través de este ${ }^{86}$.

\subsection{Procedimientos}

Los problemas que presentan los procedimientos de toma de decisiones de la administración europea son cercanos a los señalados a propósito de las estructuras organizativas. Por una parte, el procedimiento administrativo es, junto a las formas de organización, otro instrumento mediante el cual se ha alcanzado el elevado grado de integración que caracteriza a la administración europea. Con frecuencia, la aparición de agencias europeas es un paso más en el proceso de integración entre autoridades administrativas europeas y nacionales en el que previamente se ha avanzado mediante el diseño de procedimientos compuestos ${ }^{87}$. Quiere ello decir que en algunos sectores la integración se articula mediante el establecimiento de procedimientos para la gestión cooperativa o integrada de funciones administrativas, mientras que en otros ello sucede a través de la creación de un nuevo sujeto ${ }^{88}$. Las redes administrativas europeas son, en definitiva, el producto de una específica y variable combinación de estructuras organizativas y procedimentales.

Por otra parte, la regulación de los procedimientos administrativos se caracteriza por una considerable dispersión, puesto que sus fuentes se encuentran casi exclusivamente en el Derecho administrativo sectorial. Podemos observar, también en el ámbito de los procedimientos administrativos, una considerable asimetría entre la importancia de la regulación de los diversos ámbitos materiales de la administración europea y la escasa relevancia de la teoría general del Derecho administrativo. Y ello no solo desde el punto de vista de su regulación jurídica, sino también en el terreno de su tratamiento académico: al igual que se ha indicado para el caso de las estructuras organizativas, la contribución de los procedimientos administrativos al desarrollo del Derecho administrativo europeo también carece de un desarrollo adecuado en el marco de su teoría general.

Frente a esta situación, las líneas de evolución deberían comprender las dos siguientes. En primer lugar, la Unión Europea necesita mejorar la regulación general del procedimiento administrativo ${ }^{89}$. En el momento presente, las normas secunda-

${ }^{86}$ Herwig C. H. HOFMANN, Gerard C. ROWE y Alexander H. TÜRK (eds.), Specialized Administrative Law of the European Union, OUP, 2018, p. 629.

${ }^{87}$ Herwig C. H. HOFMANN, "European administration: nature and developments of a legal and political space”, en Carol HARLOW, Giacinto DELLA CANANEA y Päivi LEINO (eds.), Research Handbook on EU Administrative Law, Edward Elgar, 2017, pp. 34-35.

88 Giacinto DELLA CANANEA (2017), "The European Administration: imperium and dominium”, en Carol HARLOW, Giacinto DELLA CANANEA y Päivi LEINO (eds.), Research Handbook on EU Administrative Law, Edward Elgar, 2017, p. 61.

89 Herwig C. H. HOFMANN, Gerard C. ROWE y Alexander H. TÜRK (eds.), Administrative Law and Policy of the European Union, OUP, 2011, pp. 916-918. 
rias de aplicación horizontal son muy reducidas y los principios generales presentan un grado tal de generalidad que su aportación a la racionalización jurídica de la administración europea es más bien escasa. El excesivo grado de pluralismo regulatorio que caracteriza a los procedimientos administrativos impide al Derecho de la Unión cumplir con eficacia su función de limitar, ordenar y estabilizar la actuación de la administración europea. Es preciso, por tanto, densificar las normas sobre procedimiento de aplicación transversal, tanto en lo que atañe al desarrollo jurisprudencial de los principios generales y derechos fundamentales, como en lo que se refiere a la codificación del procedimiento administrativo de las diversas formas jurídicas de ejercicio del poder administrativo, a las que luego se hará mención. Para lo segundo, en particular, es necesario apurar las posibilidades que ofrecen las bases jurídicas contempladas en el Tratado de Funcionamiento de la Unión Europea ${ }^{90}$, empezando por la regulación de los procedimientos en los que intervienen instituciones, órganos, organismos y agencias de la Unión Europea ${ }^{91}$.

En segundo término, es conveniente profundizar en el tratamiento dogmático de los procedimientos administrativos, que pueden sistematizarse a partir de criterios diversos, atendiendo, por ejemplo, a cuáles son las autoridades que en ellos participan, a quién corresponde la competencia para resolverlo, a los tipos de intervención que pueden realizar en ellos otras autoridades ${ }^{92} \mathrm{o}$, en fin, a los eventuales efectos que esa decisión pudiera tener sobre otras actuaciones posteriores de la administración europea ${ }^{93}$. Más allá del análisis sectorial, pues, la teoría general del Derecho administrativo europeo debe tratar de aislar los tipos abstractos de procedimientos administrativos. Y para ello es preciso aplicar al tiempo dos estrategias. La primera una metodología bottom-up en la que, partiendo de los diversos regímenes sectoriales, se obtienen por abstracción pautas regulatorias comunes ${ }^{94}$. La segunda es una metodología top-down en la que se deducen exigencias constitucionales diversas a partir de los principios constitucionales relevantes -cooperación leal, buena administración, eficacia, transparencia, etcétera- ${ }^{95}$.

Esas exigencias constitucionales pueden llegar a ser muy heterogéneas, pero entre ellas es posible señalar, por su relevancia, los tres grupos siguientes. El primero es el relativo a los derechos y garantías procedimentales de los procedimientos, entre los que destacan los relativos al acceso a la información, a la audiencia o a obtener una resolución motivada. El segundo es el atinente al mandato de cuidado debido,

90 Paul CRAIG, UK, EU and Global Administrative Law, CUP, 2015, pp. 449-455.

91 Oriol MIR, Herwig C. H. HOFMANN, Jens-Peter SCHNEIDER y Jacques ZILLER, Código ReNEUAL de procedimiento administrativo de la Unión Europea, INAP, 2015.

92 Sergio ALONSO DE LEÓN, Composite Administrative Procedures in the European Union, UCLM/Iustel, 2017.

93 Herwig C. H. HOFMANN, "European administration: nature and developments of a legal and political space", en Carol HARLOW, Giacinto DELLA CANANEA y Päivi LEINO (eds.), Research Handbook on EU Administrative Law, Edward Elgar, 2017, pp. 34-36.

${ }^{4}$ Herwig C. H. HOFMANN, Gerard C. ROWE y Alexander H. TÜRK (eds.), Specialized Administrative Law of the European Union, OUP, 2018, pp. 629-638.

95 Paul CRAIG, EU Administrative Law, OUP, 2018, pp. 348-387. 
u objetividad. Una de las cuestiones que ha de resolver todo sistema de Derecho administrativo es la de si ese principio, configurado en el Derecho de la Unión como un derecho fundamental, permite otorgar relevancia anulatoria a la ausencia de determinadas actuaciones procedimentales no previstas con carácter preceptivo en la regulación del procedimiento, en la medida en que su realización sea necesaria para que la autoridad obtenga los elementos fácticos y jurídicos necesarios para poder adoptar la decisión. El tercer grupo de exigencias se refiere, en fin, a las que resultan de los derechos fundamentales y del principio de cooperación leal y que gobiernan, en particular, los mecanismos de cooperación interadministrativa relativos al intercambio de información entre las autoridades europeas e internas ${ }^{96}$.

\subsection{Formas jurídicas}

El tercer grupo de estructuras administrativas que contribuyen a incrementar el grado de sistematización del Derecho administrativo europeo es el de las formas jurídicas de actuación de la administración europea ${ }^{97}$. El estado en el que éstas se encuentran, tanto desde el punto de vista dogmático como normativo, es particularmente crítico. El primero reclama una adecuada sistematización de los diversos tipos abstractos de formalización jurídica de la actuación administrativa, a la vista de sus funciones institucionales - para qué sirve cada uno de ellos-, de sus presupuestos constitucionales -cómo deben configurarse de conformidad con el Derecho primario- y de la regulación sectorial -cómo están regulados en el Derecho secundario-. El segundo, por su parte, se refiere al diseño de un régimen jurídico adecuado para cada uno de esos tipos por parte del legislador y de los tribunales europeos. Más específicamente, la reconstrucción dogmática y normativa de las formas jurídicas de actuación de la administración ha de desarrollarse en los cuatro ámbitos siguientes.

El primero es el de la distinción entre la actividad de la administración europea que se encuentra jurídicamente formalizada y la que, por no estarlo, presenta un carácter puramente material. La primera se caracteriza por que el ejercicio de la competencia administrativa se concreta en una decisión expresada por medio de una forma de actuación regulada por el Derecho, llamada a producir efectos jurídicos en sus destinatarios y, por ello, normalmente adoptada tras la tramitación de un procedimiento administrativo. El principio de legalidad y el Estado de Derecho requieren prima facie una decisión jurídicamente formalizada para que el poder público pueda alterar las situaciones jurídicas de los destinatarios de sus decisiones. Esa decisión puede tener por objeto un supuesto de hecho concreto o abstracto. Puede también ser el producto de una actuación unilateral o consensual. De la proyección de estos

${ }^{6}$ Jens-Peter SCHNEIDER, "Information Exchange and its problems", en Carol HARLOW, Giacinto DELLA CANANEA y Päivi LEINO (eds.), Research Handbook on EU Administrative Law, Edward Elgar, 2017, pp. 81-112.

${ }_{97}$ Andreas GLASER, Die Entwicklung des Europäischen Verwaltungsrechts aus der Perspektive der Handlungsformenlehre, Mohr Siebeck, 2013. 
criterios resultan diferentes tipos abstractos que se pueden concretar jurídica y dogmáticamente de manera distinta en diferentes ordenamientos. Así, la distinción abstracta entre norma, acto y contrato se perfila en el Derecho administrativo europeo de forma diversa a como lo puede hacer en cada uno de los Derechos de los Estados miembros ${ }^{98}$, pero es perfectamente reconocible en uno y otro ámbito.

Por su parte, el contenido de la actividad administrativa de carácter material puede ser muy heterogéneo, pues lo relevante es que no se exprese a través de una decisión jurídicamente formalizada ${ }^{99}$. En la administración europea la actividad material consiste muy frecuentemente en la transmisión de información a otras autoridades y al público en general ${ }^{100}$. Sin embargo, recientemente puede observarse una creciente atribución de competencias operativas a organismos y agencias ${ }^{101}$. El Derecho administrativo europeo y su teoría general se han centrado de manera casi exclusiva en la ordenación y racionalización jurídicas de la actividad formalizada. Por el contrario, han desatendido injustificadamente las actuaciones no formalizadas jurídicamente, que plantean un problema muy relevante de efectividad de su control judicial ${ }^{102}$. El modo en que las bases constitucionales del Derecho administrativo europeo inciden en el régimen jurídico de esos actos es también incierto por lo que se refiere a la integridad del principio de legalidad, a los derechos de los particulares en relación con el desarrollo de la actividad y al derecho a obtener una compensación por los daños causados como consecuencia de ella ${ }^{103}$.

En segundo término, dentro de la actividad formalizada es preciso otorgar una mayor relevancia a la distinción entre norma y acto, es decir, entre decisiones administrativas cuyo objeto es una situación abstracta y decisiones cuyo objeto es una situación concreta. El Derecho de la Unión Europea otorga una cierta relevancia a esta distinción, en la medida en que asocia la aplicación de reglas diferentes a los actos de carácter general e individual, por ejemplo en materia de acceso a la jurisdicción (art. 263 del Tratado de Funcionamiento) o de notificación y publicación oficial (art. 297 del Tratado de Funcionamiento). Los dos criterios conducen normalmente al mismo resultado, porque las decisiones de contenido abstracto suelen tener como destinatarios a una pluralidad indeterminada de personas. Sin embargo, la categoría de los actos administrativos generales, bien conocida en el Derecho administrativo

98 Andreas GLASER, Die Entwicklung des Europäischen Verwaltungsrechts aus der Perspektive der Handlungsformenlehre, Mohr Siebeck, 2013, pp. 332-407, 289-318.

99 Andreas GLASER, Die Entwicklung des Europäischen Verwaltungsrechts aus der Perspektive der Handlungsformenlehre, Mohr Siebeck, 2013, pp. 404-407.

100 Jens-Peter SCHNEIDER, "Information Exchange and its problems", en Carol HARLOW, Giacinto DELLA CANANEA y Päivi LEINO (eds.), Research Handbook on EU Administrative Law, Edward Elgar, 2017, pp. 81-112.

101 David FERNÁNDEZ-ROJO, Evolution of the Operational Tasks of FRONTEX, EASO and EUROPOL, Tesis doctoral, Universidad de Deusto, 2018.

102 Napoleon XANTHOULIS, "Administrative factual conduct: Legal effects and judicial control in EU law”, Review of European Administrative Law, vol. 12, núm. 1, 2019, pp. 39-73.

103 Herwig C. H. HOFMANN, Gerard C. ROWE y Alexander H. TÜRK, Administrative Law and Policy of the European Union, OUP, 2011, p. 915. 
continental, pone de manifiesto que puede haber decisiones que se proyectan sobre un objeto concreto, pero se dirigen a una pluralidad indeterminada de personas. En todo caso, el protagonismo de la diferencia entre norma y acto es en el Derecho de la Unión Europea mucho menor que el que adquiere en los Derechos administrativos de los Estados miembros y en el Derecho comparado. Baste señalar como ejemplo que el deber de motivación no se frena ante el carácter normativo de la decisión adoptada (art. 296.2 del Tratado de Funcionamiento de la Unión Europea).

El Derecho secundario debe proporcionar una regulación específica más refinada de cada una de estas dos formas de actuación, relacionada con los procedimientos de su adopción, con su comunicación formal a sus destinatarios, con el régimen de validez y eficacia, con el régimen de impugnación jurisdiccional, etc. ${ }^{104}$. Las recomendaciones del Parlamento Europeo a la Comisión acerca de una Ley de Procedimiento Administrativo de la Unión Europea establecían reglas sobre actos administrati$\operatorname{vos}^{105}$. Igualmente, las determinaciones del Código de Buena Conducta Administrativa aprobado por el Defensor de Pueblo Europeo ${ }^{106}$ están diseñadas específicamente para el caso de actos y no de normas ${ }^{107}$. La propuesta de Código de procedimiento administrativo elaborada por la red ReNEUAL, en fin, comprende estas dos formas jurídicas, aunque somete los actos y las normas elaboradas por la administración europea a regímenes jurídicos distintos ${ }^{108}$. Por su parte, la teoría general del Derecho administrativo europeo ha de precisar los criterios y el funcionamiento de la distinción entre las dos categorías, si es que de la aplicabilidad de una de ellas se han de deducir y aplicar consecuencias tan importantes respecto de su régimen jurídico ${ }^{109}$.

En tercer lugar, el régimen jurídico de las normas que puede aprobar la administración europea presenta carencias relevantes. No solo es preciso diseñar un régimen general de mínimos aplicable a la aprobación de cualesquiera disposiciones normativas, que permita garantizar la satisfacción de principios constitucionales relevantes como los de participación, transparencia, y control judicial de la administración europea. También es necesario revisar la distinción entre actos delegados y actos de

104 Oriol MIR, "La codificación del procedimiento administrativo en la Unión administrativa europea”, en Francisco VELASCO y Jens-Peter SCHNEIDER (eds.), La unión administrativa europea, Marcial Pons, 2008, pp. 51-85.

105 Resolución del Parlamento Europeo, de 15 de enero de 2013, con recomendaciones destinadas a la Comisión sobre una Ley de Procedimiento Administrativo de la Unión Europea [2012/2024(INL)]; Resolución del Parlamento Europeo, de 9 de junio de 2016, para una administración de la Unión Europea abierta, eficiente e independiente [2016/2610(RSP)].

106 Defensor del Pueblo Europeo (2015), Código de Buena Conducta Administrativa.

107 Paul CRAIG, EU Administrative Law, OUP, 2019, p. 278.

108 Oriol MIR, Herwig C. H. HOFMANN, Jens-Peter SCHNEIDER y Jacques ZILLER, Código ReNEUAL de procedimiento administrativo de la Unión Europea, INAP, 2015, libros II (normas) y III (actos).

109 Herwig C. H. HOFMANN, Gerard C. ROWE y Alexander H. TÜRK, Administrative Law and Policy of the European Union, OUP, 2011, pp. 534-586, y 625-650; Andreas GLASER, Die Entwicklung des Europäischen Verwaltungsrechts aus der Perspektive der Handlungsformenlehre, Mohr Siebeck, 2013, passim. 
ejecución. La afirmación de que la elección descansa sobre criterios jurídicos -y es, por tanto, revisable en sede judicial-, las importantes diferencias de carácter procedimental entre uno y otro tipo normativo -que se reflejan en diferentes posiciones procedimentales de los actores implicados-, así como la poca densidad normativa de la regulación de los criterios que determinan cuándo procede utilizar cada uno de ellos -tanto en el plano del Derecho primario, como en el de su configuración jurisprudencial-, han conducido a un déficit de transparencia, claridad y racionalización jurídica de la utilización de ambos tipos normativos ${ }^{110}$. Por lo demás, la decisión de reservar la noción de acto legislativo para aquellas normas externas aprobadas por ciertas instituciones y a través de un procedimiento determinado, lejos de esconder la naturaleza de las normas aprobadas por la Comisión ${ }^{111}$, refleja la tradición del Derecho público continental que funda la distinción entre normas legislativas y reglamentarias en consideraciones subjetivas y procedimentales, y no tanto en que su contenido produzca o no efectos externos de carácter general ${ }^{112}$.

Por último, algo parecido sucede en relación con la actividad de la administración europea que no tiene carácter normativo, dentro de la cual es preciso identificar reglas específicas de aplicación transversal para las decisiones administrativas de carácter unilateral, para los contratos administrativos y para las actuaciones de carácter material. El diseño de un régimen general -abierto, claro está, a diversas concreciones sectoriales- para cada forma jurídica de actuación facilita una aplicación coherente de las bases constitucionales del Derecho administrativo europeo, incrementa la transparencia y previsibilidad del Derecho administrativo europeo, y mejora la racionalización jurídica de la actuación de la administración europea ${ }^{113}$. Se trata, en definitiva, de una tarea imprescindible para la construcción del sistema del Derecho administrativo europeo.

\section{CONCLUSIONES}

El Derecho administrativo europeo es un instrumento de dirección de procesos sociales que, en su estado actual, presenta algunas debilidades importantes. En esta contribución he sugerido que una vía para perfeccionarlo es desarrollar su teoría general a partir de un pensamiento orientado al sistema y he explicado cómo creo que debería acometerse. La finalidad de la actividad de sistematización es describir e in-

110 Herwig C. H. HOFMANN, Gerard C. ROWE y Alexander H. TÜRK, Administrative Law and Policy of the European Union, OUP, 2011, pp. 924-925; P. CRAIG, EU Administrative Law, OUP, 2018, p. 129.

111 Así, P. CRAIG, EU Administrative Law, OUP, 2018, pp. 28-129.

112 Bernard STIRN, Les sources constitutionnelles du droit administratif, LGDJ, 2014, pp. 59-80; Frank REIMER, "Das Parlamentsgesetz als Steuerungsmittel und Kontrollmasstab", en Wofgang HOFFMANN-RIEM, Eberhard SCHMIDT-ASSMANN y Andreas VOSSKUHLE (Hrsg.), Grundlagen des Verwaltungsrechts, vol. I, C. H. Beck, 2006, pp. 15-23.

113 Andreas GLASER, Die Entwicklung des Europäischen Verwaltungsrechts aus der Perspektive der Handlungsformenlehre, Mohr Siebeck, 2013, pp. 60-63. 
crementar el grado de unidad y coherencia del Derecho administrativo europeo. Las estrategias metodológicas adecuadas pasan por obtener criterios orientadores procedentes de sus bases constitucionales, del régimen aplicable a los diversos sectores de referencia, del Derecho comparado y de otras disciplinas desde las que también se estudia el funcionamiento de los sistemas jurídicos.

La sistematización del Derecho administrativo europeo requiere operar tanto sobre sus elementos sustantivos - principios constitucionales, fines legislativos y criterios discrecionales-, como sobre los que tienen un carácter estructural -organización, procedimiento y formas jurídicas de actuación-. Estas dos vías deben, además, desarrollarse de manera simultánea e integrada: las propiedades formales abstractas de una determinada estructura organizativa o de un tipo procedimental nos ayudan a comprender para qué pueden servir mejor; y, al contrario, la regulación normativa y la elaboración dogmática de aquellas estructuras debe tratar de optimizar la satisfacción de las tareas que le son propias. En definitiva, forma y función, lejos de ser estrategias alternativas ${ }^{114}$, son los dos espacios en los que se debe desarrollar simultáneamente la actividad de sistematización del Derecho administrativo europeo.

La finalidad de este programa de investigación es ambiciosa, pero no se encuentra exenta de límites. En particular, no puede olvidarse que las exigencias y condiciones de la regulación en cada ámbito de políticas públicas pueden ser muy heterogéneas. El papel de la teoría general del Derecho administrativo europeo no puede ser, por tanto, encontrar en sus bases constitucionales, en alguna regulación sectorial o en el Derecho comparado la técnica de organización o de funcionamiento idónea para cada ámbito material de la administración europea. Su tarea, más prudente, es la de sugerir criterios que ordenen la deliberación acerca de la producción y la interpretación de las normas del Derecho administrativo europeo. Tal y como se ha indicado antes, nose trata, en definitiva, de sustituir la experimentación por el sistema, sino de mejorar la primera a través del segundo ${ }^{115}$.

114 Patrick HILBERT, Systemdenken in Verwaltungsrecht und Verwaltungsrechtswissenschaft, Mohr Siebeck, 2015, pp. 76-77.

115 Herwig C. H. HOFMANN, Gerard C. ROWE y Alexander H. TÜRK (eds.), Specialized Administrative Law of the European Union, OUP, 2018, p. 629. 
